\title{
Beetroot enriched bread consumption reduces blood pressure in normotensive males: a pilot study
}

\author{
D. A. Hobbs ${ }^{1,2}$, T. W. George $\mathrm{e}^{1,2}$, L. Methven ${ }^{1}$ and J. A. Lovegrove ${ }^{1,2}$ \\ ${ }^{1}$ Department of Food and Nutritional Sciences, University of Reading, Whiteknights, PO Box 226, Reading, Berks, \\ RG6 6AP, UK and ${ }^{2}$ Institute for Cardiovascular and Metabolic Research (ICMR), University of Reading, Whiteknights, PO \\ Box 226, Reading, Berks, RG6 6AP, UK
}

High blood pressure (BP) or hypertension $(\mathrm{BP}>140 / 90 \mathrm{mmHg}$ ) is an independent risk factor for CVD. Individuals with uncontrolled hypertension pose a 3 -fold higher risk of developing CVD compared with normotensives ${ }^{(1)}$. Vegetables, particularly green leafy and beetroot are abundant in nitrate $\left(\mathrm{NO}_{3}{ }^{-}\right)$, which after ingestion can be reduced to nitrite $\left(\mathrm{NO}_{2}{ }^{-}\right)$by oral bacteria, and further to the vasodilator nitric oxide (NO) endogenously ${ }^{(2)}$. Beetroot juice $(500 \mathrm{ml})$ has been shown to lower systolic BP (SBP) by $10 \mathrm{mmHg}$ in healthy individuals ${ }^{(3)}$. A pilot study was designed to investigate the effects of enriching bread with two different varieties of beetroot on $24 \mathrm{~h}$ ambulatory BP (ABP).

Fourteen healthy male participants were recruited to a randomly controlled, single blind, cross-over, postprandial test meal study. ABP was measured at baseline, every $15 \mathrm{~min}$ for $4 \mathrm{~h}$, followed by every $30 \mathrm{~min}$ for $9 \mathrm{~h}$ and hourly overnight after consumption of $200 \mathrm{~g}$ of two novel bread products enriched with either $100 \mathrm{~g}$ white beetroot $\left(5.0 \mathrm{mM} \mathrm{NO}_{3}{ }^{-}\right)$or $100 \mathrm{~g}$ red beetroot $\left(5.6 \mathrm{mM} \mathrm{NO}_{3}{ }^{-}\right)$and control bread containing no beetroot. White beetroot lack betalains, a group of nitrogenous pigments which are particularly abundant in red beetroot, therefore the differential effects on BP by the elimination of betalains was also demonstrated. Urine samples were collected at baseline, 2 , 4 and $24 \mathrm{~h}$. The participants followed a low nitrate and nitrite diet for $48 \mathrm{~h}$ prior to and during the study day. A low nitrate and nitrite standard meal was provided for the evening before the study day.

A significant reduction in diastolic BP (DBP) was observed approximately 2-3 h post ingestion, in the order of 19.4 (SEM 6.9) and 19.4 (SEM 8.5) $\mathrm{mmHg}(P<0.05)$ for white and red enriched beetroot bread, respectively. Incremental area under the curve (IAUC) for DBP was significantly lower from baseline to $4 \mathrm{~h}$ post ingestion after both beetroot enriched breads (Fig. 1A) and was significantly lower for red beetroot enriched bread for the remaining $24 \mathrm{~h}(P<0.50)$. Summation measures for urinary nitrates and nitrites $(\mathrm{NO} x)$ were significantly increased from 0 to 2 and $4 \mathrm{~h}$ post consumption of beetroot enriched breads $(P<0.05)$ compared with the control bread (Fig. 1B).
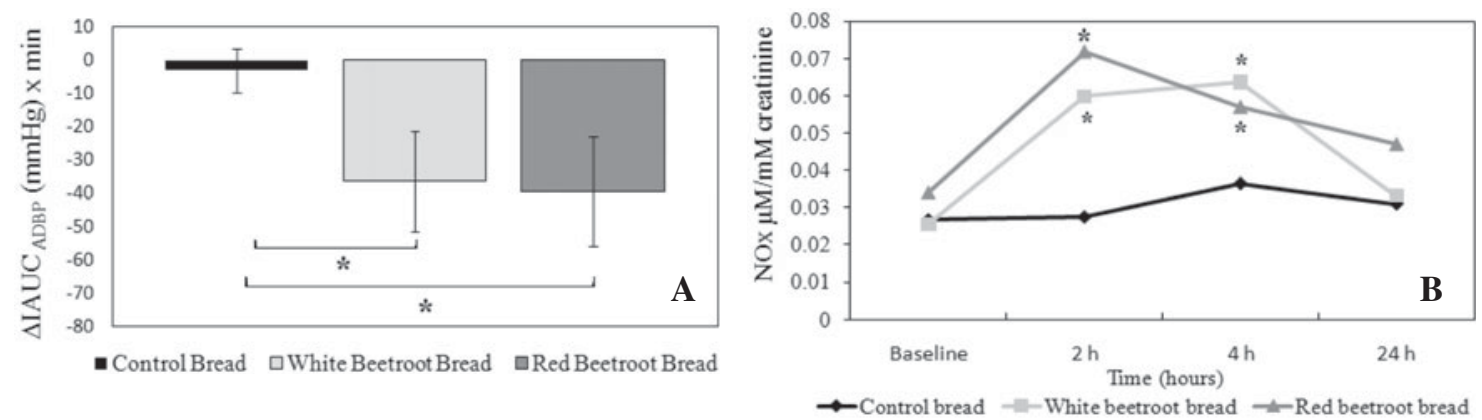

Fig. 1. (A) The percentage change in IAUC for DBP from baseline to $4 \mathrm{~h}$ after consumption of control bread (no beetroot), white or red beetroot enriched breads ( $^{*}=P<0.05 v$. control) and (B) mean urinary NOx concentration at baseline, 2, 4 and $24 \mathrm{~h}$ after consumption of control bread (no beetroot), white or red beetroot enriched bread $(*=P<0.05 v$. control) (mean SE)

In conclusion, this study demonstrated that bread products enriched with white or red beetroot significantly lowered BP and increased urinary NOx with no statistical differences between varieties in healthy males. This data suggests that the beneficial effects of beetroot on $\mathrm{BP}$ is likely to be due in part to its high $\mathrm{NO}_{3}{ }^{-}$content and that processing had minimal impact.

1. Wang W, Lee ET, Fabsitz RR et al. (2006) Hypertension 47, 403-409.

2. Lundberg JO, Weitzberg E \& Gladwin MT (2008) Nat Rev Drug Discov 7, 156-167.

3. Webb AJ, Patel N, Loukogeorgakis S et al. (2008) Hypertension 51, 784-790. 